\title{
Role of Glucose Transporters in the Cellular Insulin Resistance of Type II Non-Insulin-dependent Diabetes Mellitus
}

\author{
W. Timothy Garvey, Thomas P. Huecksteadt, Stephan Matthaei, and Jerrold M. Olefsky \\ Division of Endocrinology and Metabolism, Department of Medicine, University of California San Diego School of Medicine, La Jolla, \\ California 92093; and the Veterans Administration Medical Center, Medical Research Service, San Diego, California 92161
}

\begin{abstract}
To examine the role of glucose transport proteins in cellular insulin resistance, we studied subcutaneous adipocytes isolated from lean control, obese control (body mass index [BMI] $33.4 \pm 0.9$ ), and untreated obese non-insulin-dependent diabetes mellitus (NIDDM) patients (BMI 35.2 \pm 2.1 ; fasting glucose $269 \pm 20 \mathrm{mg} / \mathrm{dl})$. Glucose transporters were measured in plasma membrane (PM), low-density (LDM), and high-density (HDM) microsomal subfractions from basal and maximally insulin-stimulated cells using the cytochalasin B binding assay, and normalized per milligram of membrane protein. In all subgroups, insulin led to an increase in PM glucose transporters and a corresponding depletion of transporters in the LDM. Insulin recruited $20 \%$ fewer transporters to the PM in the obese subgroup when compared with lean controls, and this was associated with a decline in LDM transporters with enlarging cell size in the control subjects. In NIDDM, PM, and LDM, transporters were decreased $50 \%$ in both basal and stimulated cells when compared with obese controls having similar mean adipocyte size. Cellular depletion of glucose transporters was not the only cause of insulin resistance, because the decrease in rates of $\left[{ }^{14} \mathrm{C}\right]$-D-glucose transport (basal and insulin-stimulated) was greater than could be explained by reduced numbers of PM transporters in both NIDDM and obesity. In HDM, the number of transporters was not influenced by insulin and was similar in all subgroups. We conclude that $(a)$ in NIDDM and obesity, both reduced numbers and impaired activity of glucose transporters contribute to cellular insulin resistance, and (b) in NIDDM, more profound cellular insulin resistance is associated primarily with a further depletion of cellular transporters.
\end{abstract}

\section{Introduction}

In type II non-insulin-dependent diabetes mellitus (NIDDM $)^{1}$, studies have shown that a defect distal to receptor

Portions of this work were presented at the annual meeting of the American Diabetes Association, Indianapolis, IN, June 1987.

Address reprint requests to Dr. Wm. Timothy Garvey, University of California, San Diego, Department of Medicine M-023E, La Jolla, CA 92093.

Received for publication 13 July 1987 and in revised form 19 October 1987.

1. Abbreviations used in this paper: BMI, body mass index; HDM, high-density microsomal subfraction; $K_{d}$, dissociation constant; LDM, low-density microsomal subfraction; NIDDM, non-insulin-dependent diabetes mellitus; PM, plasma membrane microsomal subfraction.

J. Clin. Invest.

(C) The American Society for Clinical Investigation, Inc.

0021-9738/88/05/1528/09 \$2.00

Volume 81, May 1988, 1528-1536 binding in the insulin action sequence is the major abnormality that impairs insulin's ability to stimulate glucose disposal in vivo $(1,2)$. Adipocytes isolated from these patients have been studied as a classic insulin target tissue to further explore the cellular locus of this defect $(3,4)$. In these cells, decreased basal and insulin-stimulated glucose transport rates found in vitro (3-6) corresponded well to the in vivo expression of the postbinding defect (2, 7-9), and suggested that at least one cellular abnormality in NIDDM is intrinsic to the glucose transport effector system. However, the molecular mechanisms responsible for cellular insulin resistance in NIDDM are unknown.

Recently, Cushman and associates (10-12) and Kono and associates $(13,14)$ have shown that insulin activates glucose transport in rat adipocytes through a rapid, reversible, and concentration-dependent translocation of glucose transporters from a large intracellular pool (associated with low-density microsomes) to the plasma membrane. This mechanism for stimulation of glucose transport was later shown to be operative in other insulin target tissues such as rat diaphragm (15) and heart (16), but not in cells lacking an insulin response, such as hepatocytes (17). We (18) and others (19) have also demonstrated insulin-induced recruitment of transporters in human adipocytes. In the context of this translocation model, a defect in insulin-stimulated glucose transport could involve an abnormality in either the number (20), function, or recruitment (21) of glucose transporters. In the current study, we have examined these parameters in adipocytes to help elucidate the mechanisms causing insulin resistance in NIDDM and obesity.

\section{Methods}

Subjects. The clinical characteristics of the study groups are listed in Table I. The control groups consisted of 12 healthy lean male subjects, all of whom had a body mass index (BMI) of $<27$, and 11 healthy obese subjects, including eight males and three females, with BMI ranging from 29.2 to 38.2. The mean ( $\pm \mathrm{SE}$ ) age was similar in the lean and obese control groups $(P=N S)$. All lean and obese control subjects had normal fasting plasma glucose levels, whereas the obese individuals displayed basal hyperinsulinemia. Furthermore, all control subjects were found to have normal (22) oral glucose tolerance tests (Fig. 1).

Seven male and four female patients with NIDDM as defined by the National Diabetes Data Group (22) were also studied. The mean $( \pm \mathrm{SE})$ duration of disease was $6 \pm 2 \mathrm{yr}$, including two subjects with newly diagnosed diabetes who had developed hyperglycemic symptoms within 6 mo of study. Of the nine previously diagnosed patients, two had been treated with diet, six with oral hypoglycemic agents, and one with insulin. Before the study, however, all diabetic patients were withdrawn from therapy for at least 2 wk and followed on an outpatient basis. As can be seen in Table I, the untreated diabetic patients exhibited overt fasting hyperglycemia with mean $( \pm S E)$ fasting plasma glucose $269 \pm 20 \mathrm{mg} / \mathrm{dl}$. All NIDDM subjects were obese, with BMI ranging from 31 to 47 . The mean value was similar to that in obese controls $(P=\mathrm{NS})$. The mean $( \pm \mathrm{SE})$ age was $44 \pm 3 \mathrm{yr}$ in the NIDDM 
Table I. Clinical Characteristics

\begin{tabular}{lcccc}
\hline & \multicolumn{2}{c}{ Controls } & & NIDDM \\
\cline { 2 - 3 } \cline { 5 - 5 } & Lean & Obese & & Obese \\
\hline Number & 12 & 11 & 11 \\
Age $(y r)$ & $35 \pm 3$ & $37 \pm 3$ & & $44 \pm 3$ \\
Gender $(\mathrm{M} / \mathrm{F})$ & $12 \mathrm{M}$ & $8 \mathrm{M} / 3 \mathrm{~F}$ & & $7 \mathrm{M} / 4 \mathrm{~F}$ \\
Body mass index & $25.1 \pm 0.5$ & $33.4 \pm 0.9$ & & $35.2 \pm 2.1$ \\
Fasting glucose $(m g / d l)$ & $93 \pm 3$ & $95 \pm 4$ & & $269 \pm 20$ \\
Fasting insulin $(U / m l)$ & $6 \pm 1$ & $20 \pm 3$ & & $17 \pm 2$ \\
Mean adipocyte size $(p l)$ & $364 \pm 31$ & $733 \pm 60$ & & $713 \pm 47$ \\
\hline
\end{tabular}

patients, not significantly different from the mean ages in the control subgroups ( $P=$ NS, one-way analysis of variance). All NIDDM and control subjects were chemically euthyroid, and without renal, hepatic, or cardiac disease. No subject was ingesting pharmacological agents known to affect carbohydrate homeostasis.

The mean $( \pm$ SE) cell volume of isolated subcutaneous adipocytes is also shown in Table I for each of the subject groups. The value in the obese NIDDM patients ( $713 \pm 47 \mathrm{pl})$ was statistically similar $(P=\mathrm{NS})$ to that in obese controls $(733 \pm 60 \mathrm{pl})$, and both values were elevated $(P<0.01)$ relative to that observed in the lean control subjects $(364 \pm 31 \mathrm{pl})$.

Protocol. After giving informed consent, all subjects were hospitalized on a metabolic ward where they remained active. The subjects were allowed to equilibrate on a weight-maintenance prescribed diet (32 kcal $/ \mathrm{kg}$ per d), consisting of $45 \%$ carbohydrate, $40 \%$ fat, and $15 \%$ protein for $2 \mathrm{~d}$. Standard 75-g oral glucose tolerance tests were performed, and, on the next morning, 14-45 $\mathrm{g}$ of subcutaneous adipose tissue was obtained by open biopsy of the lower abdominal wall using methods previously described (23). Isolated adipocytes were prepared from each subject by collagenase digestion and glucose transport assays were performed on a small aliquot of these cells. The majority of adipocytes was homogenized and membrane subfractions were prepared by differential centrifugation. In some cases, to obtain enough membrane protein for assays (see below), adipocytes from two subjects were combined before homogenization. Specifically, adipocytes from all 12 lean controls, 10 of 11 obese controls, and 6 of 11 NIDDM subjects were paired resulting in six, six, and eight membrane preparations in these subgroups, respectively. Within each subgroup, adipocytes were combined only when two subjects were matched for gender, age $( \pm 10 \%)$, and $\mathrm{BMI}( \pm 9 \%)$.

Preparation of adipocytes and subcellular membrane fractions. Biopsied adipose tissue was placed immediately into Krebs-Ringer phosphate buffer, pH 7.4, containing $10 \mathrm{mM}$ Hepes, $2.5 \mathrm{mM}$ $\mathrm{NaH}_{2} \mathrm{PO}_{4}, 4 \%$ BSA (fraction V; Boehringer Mannheim Biochemicals, Indianapolis, IN), and $5 \mathrm{mM}$ D-glucose. The specimens were brought quickly to the laboratory, trimmed of connective tissue, and weighed. The tissue was minced with fine scissors and isolated adipocytes were

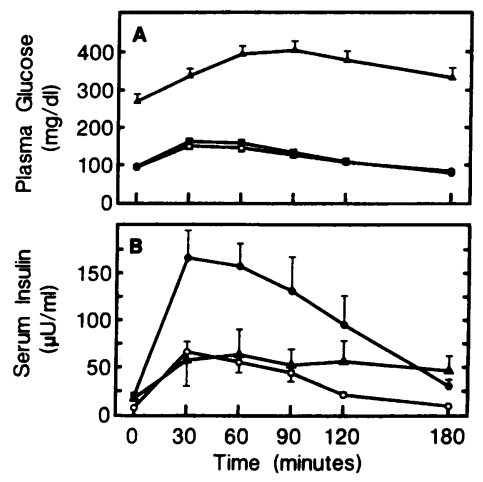

Figure 1. Oral glucose tolerance tests. The data are the mean $\pm \mathrm{SE}$ of plasma glucose $(A)$ and serum insulin $(B)$ levels in lean control (O), obese control (๑), and obese NIDDM ( $\Delta$ ) subjects after a 75-g oral glucose challenge. obtained by gently shaking the tissue in polypropylene containers at $37^{\circ} \mathrm{C}$ for $1 \mathrm{~h}$ in the same buffer $(0.5 \mathrm{~g} / \mathrm{ml})$ containing $1 \mathrm{mg} / \mathrm{ml}$ collagenase (Cooper Biomedical, Freehold, NJ). The adipocytes were then washed in the Krebs-Ringer phosphate buffer without glucose and collagenase $\left(37^{\circ} \mathrm{C}\right)$, and a small aliquot was removed for immediate cell sizing, counting, and glucose transport assays. The remaining cells were divided equally into $950-\mathrm{ml}$ polypropylene jars and incubated for $30 \mathrm{~min}$ at $37^{\circ} \mathrm{C}(5-8 \%$ cells/volume suspension) in the absence and presence of $100 \mathrm{ng} / \mathrm{ml}$ insulin. The term basal cells refers to those cells incubated in the absence of insulin.

To study the number and cellular distribution of adipocyte glucose transporters under basal and insulin-stimulated conditions, plasma membrane (PM), and low-density (LDM) and high-density (HDM) microsomal membrane subfractions were prepared from these cells using a modification of the differential centrifugation method described by McKeel and Jarett (24). Incubated cells were washed twice in pH 7.4 buffer containing $20 \mathrm{mM}$ Tris- $\mathrm{HCl}, 255 \mathrm{mM}$ sucrose, $1 \mathrm{mM}$ EDTA, and protease inhibitors (Sigma Chemical Co., St. Louis, MO), including $5 \mathrm{mg} / \mathrm{ml}$ leupeptin, $5 \mathrm{mg} / \mathrm{ml}$ pepstatin, and $5 \mathrm{mg} / \mathrm{ml}$ aprotinin, and then homogenized at $17^{\circ} \mathrm{C}$ in a glass homogenizer with a Teflon pestle (Arthur H. Thomas Co., Philadelphia, PA). All subsequent steps were carried out at $4^{\circ} \mathrm{C}$ in the same buffer. Each homogenate from basal and insulin-stimulated cells was centrifuged at 16,000 $g$ for $20 \mathrm{~min}$; the supernatant was saved and the fat cake was discarded. The pellet was washed once (by resuspension in buffer and recentrifugation at $16,000 \mathrm{~g}$ for $20 \mathrm{~min}$ ), resuspended in buffer, layered on top of a $1.12-\mathrm{M}$ sucrose cushion containing $20 \mathrm{mM}$ Tris- $\mathrm{HCl}$ and $1 \mathrm{mM}$ EDTA, and centrifuged at $101,000 \mathrm{~g}$ for $60 \mathrm{~min}$ in a SW28 rotor (Beckman Instruments, Inc., Fullerton, CA). This allowed separation of nuclei and mitochondria (bottom) from plasma membranes that remained on top of the $1.12 \mathrm{M}$ sucrose. The plasma membranes were collected and washed once in buffer by recentrifugation at $48,000 \mathrm{~g}$ for $45 \mathrm{~min}$. The microsomes were obtained from supernatant, by centrifugation at $48,000 \mathrm{~g}$ for $20 \mathrm{~min}$, yielding an HDM pellet, and by recentrifugation of the $48,000 \mathrm{~g}$ supernatant at $340,000 \mathrm{~g}$ for $100 \mathrm{~min}$ to pellet LDM. The plasma membrane and both microsomal pellets were resuspended in buffer to a final concentration of $1-3 \mathrm{mg}$ protein $/ \mathrm{ml}$ and stored frozen at $-70^{\circ} \mathrm{C}$.

Assays. In each subject, the adipocyte diameter of 200 cells was measured using a cell-counting chamber and eyepiece micrometer, and the mean value was used to calculate adipocyte volume assuming that the cells were spherical. Adipocyte counts were performed according to a modification of method III of Hirsch and Gallian (25) as previously described (26). Cellular transport rates of trace $\left[{ }^{14} \mathrm{C}\right]$-D-glucose were determined as described by Foley and co-workers $(6,27)$. In this assay, isolated adipocytes ( $2 \%$ lipocrit, volume $500 \mu \mathrm{l}$ ) were incubated $\left(37^{\circ} \mathrm{C}\right)$ in Krebs-Ringer phosphate buffer, $\mathrm{pH} 7.4$, containing 10 $\mathrm{mM}$ Hepes and $4 \% \mathrm{BSA}$ with and without maximal insulin $(100$ $\mathrm{ng} / \mathrm{ml})$ in the presence of $300 \mathrm{nM}\left[{ }^{14} \mathrm{C}\right]-(u)$-D-glucose $(359 \mathrm{mCi} / \mathrm{mmol}$; New England Nuclear, Boston, MA). The incubation was terminated after $1 \mathrm{~h}$ by centrifuging a $400-\mu \mathrm{l}$ aliquot of cells through oil, and uptake of $\left[{ }^{14} \mathrm{C}\right]-(l)$-L-glucose (New England Nuclear, Boston, MA) was used to correct for nonspecific carryover of radioactivity with the cells, even though this value was $<5 \%$ of $\left[{ }^{14} \mathrm{C}\right]$-D-glucose uptake. This method is based on the premise that glucose uptake provides a measurement of glucose transport when studies are carried out at low glucose concentrations (i.e., independent of cellular D-glucose metabolism), and in human adipocytes, provides results similar to those obtained with the 3-0-methylglucose rapid-pulse technique $(6,27)$.

The number of glucose transporters was measured in each membrane subfraction as the number of D-glucose-inhibitable cytochalasin $B$ binding sites as previously described (10-12). In the presence of 5 $\mu \mathrm{M}$ cytochalasin $\mathrm{E}$, cytochalasin $\mathrm{B}$ binding at five ligand concentrations (42-420 nM) was measured at $4^{\circ} \mathrm{C}$ using 35-50 $\mu \mathrm{g}$ membrane protein (total volume $60 \mu \mathrm{l}$ ) in the absence and presence of $500 \mathrm{mM}$ D-glucose; the difference in binding was taken as the D-glucose-inhibitable component. The number of these binding sites $\left(R_{\mathrm{o}}\right)$ and the dissociation constant $\left(K_{d}\right)$ were determined by Scatchard analysis. 
In the homogenate and in each membrane subfraction, we measured various organelle marker enzymes, including 5'-nucleotidase activity, using the method of Avruch and Wallach (28); uridine 5' diphosphate-galactose/ $\mathrm{N}$-acetylglucosamine galactosyltransferase activity using the method of Fleisher (29); and rotenone-insensitive NADH-cytochrome $c$ reductase according to Dallner et al. (30). Also, protein was measured by the Coomassie Brilliant Blue method described by Bradford (31) using crystalline BSA as the standard (BioRad protein assay; Bio-Rad Laboratories, Richmond, CA).

Plasma glucose was measured by the glucose oxidase method using a glucose analyzer (Beckman Instruments, Inc.). Serum insulin levels were measured by a double antibody RIA using the method of Desbuquois and Aurbach (32). Serum-free insulin levels were measured in the diabetic subject previously treated with insulin as described by Kuzuya et al. (33).

Means are given as mean $\pm \mathrm{SE}$ and statistical significance was determined using one-way or two-way analysis of variance where appropriate and the Duncan's Multiple Comparison Test as a posthoc test.

\section{Results}

Oral glucose tolerance tests. As can be seen in Fig. 1, mean plasma glucose values were normal in the lean and obese control subjects under basal conditions and at all time points after an oral glucose challenge, while the untreated NIDDM patients displayed overt hyperglycemia between $269 \pm 20$ and $404 \pm 24 \mathrm{mg} / \mathrm{dl}$. Normoglycemia in the obese controls was observed in association with elevated serum insulin levels ranging from $20 \pm 3 \mu \mathrm{U} / \mathrm{ml}$ (fasting) to $166 \pm 29 \mu \mathrm{U} / \mathrm{ml}$ (30 min), whereas the overall insulin curve in the NIDDM patients was not statistically different from that in lean control subjects $(P$ $=\mathrm{NS}$ ). Euglycemia in conjunction with hyperinsulinemia in the obese controls and hyperglycemia despite a normal insulin response in NIDDM are indicative of peripheral insulin resistance $(1,2)$.

Glucose transport activity. Using a peripheral target tissue, we studied insulin's ability to stimulate glucose transport in vitro. Basal and maximally insulin-stimulated rates of $\left[{ }^{14} \mathrm{C}\right]-\mathrm{D}-$ glucose transport were measured in intact adipocytes isolated from lower abdominal wall biopsy specimens in each patient, and mean values are shown in each subject group normalized per cell in Fig. $2 A$ and per cell surface area in Fig. $2 B$. When

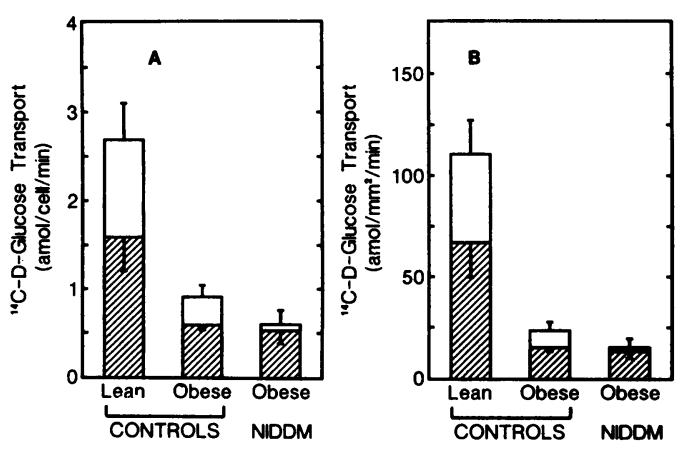

Figure 2. Glucose transport rates in isolated human adipocytes. Mean \pm SE $\left[{ }^{14} \mathrm{C}\right]-\mathrm{D}$-glucose transport rates (attomoles per minute) are shown in isolated adipocytes from lean and obese control and obese NIDDM subjects and normalized per cell $(A)$ and per cell surface area $(B)$. Adipose tissue was obtained by subcutaneous biopsy from the lower abdominal wall and cells isolated by collagenase digestion. Cellular transport rates of trace $\left[{ }^{14} \mathrm{C}\right]$-D-glucose $(300 \mathrm{nM})$ were determined as described by Foley et al. $(6,27)$. compared with lean controls, basal and maximal glucose transport rates were decreased $(P<0.01)$ in both obese subgroups, whether expressed per cell $(63-77 \%)$ or per cell surface area $(76-86 \%)$. When only the obese subgroups were considered, basal transport rates were $10-13 \%$ lower in the diabetic patients than in the obese control subjects, but this difference did not achieve statistical significance $(P=N S)$. However, insulin resistance was more profound in the adipocytes from the obese NIDDM patients; maximally stimulated glucose transport rates per cell and per cell surface were decreased by 33\% $(P<0.05)$ compared with obese controls. No significant differences were found in either basal or maximal glucose transport rates between male and female subjects in either the obese or NIDDM groups.

Number and distribution of cellular glucose transporters. To elucidate the mechanism underlying the decrease in insulin responsiveness, we measured the number and cellular distribution of glucose transport proteins. Adipocytes from control and diabetic subjects were preincubated in the absence (basal) and presence of a maximal insulin concentration $\left(37^{\circ} \mathrm{C} ; 30\right.$ min), homogenized, and subjected to a differential centrifugation protocol for isolating membrane subfractions. Fig. 3 shows mean values of D-glucose-inhibitable $\left[{ }^{3} \mathrm{H}\right]$ cytochalasin $B$ binding to PM and LDM, and the data reveal quantitative differences between the subgroups. In basal cells, the concentration of PM glucose transporters was similar $(P=N S)$ in lean and obese controls $(4.4 \pm 0.3$ vs. $4.2 \pm 0.3 \mathrm{pmol} / \mathrm{mg}$ protein) but decreased by $\sim 50 \%(P<0.01)$ in NIDDM $(2.1 \pm 0.2 \mathrm{pmol} /$ $\mathrm{mg}$ ). In the LDM, however, obesity per se was associated with depleted numbers of glucose transporters; the mean concentration in obese controls was reduced by $40 \%$ to $6.8 \pm 0.5$ $\mathrm{pmol} / \mathrm{mg}(P<0.01)$ compared with the value of $11.4 \pm 1.2$

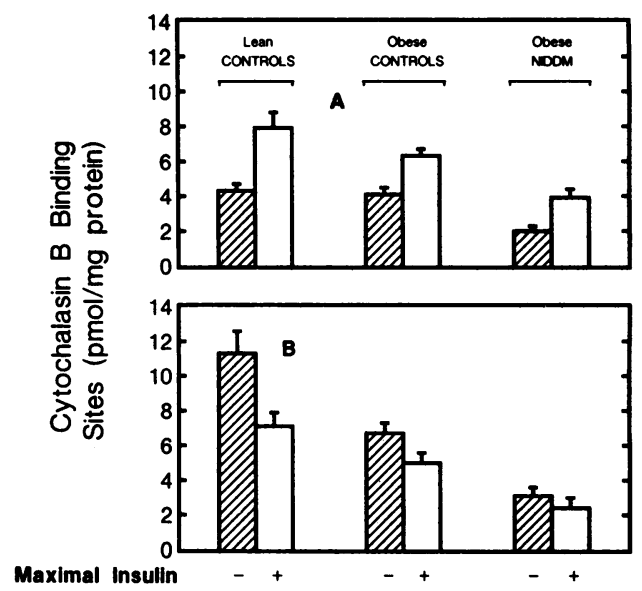

Figure 3. D-Glucose-inhibitable cytochalasin B binding to adipocyte membrane subfractions. Isolated adipocytes were prepared from lower abdominal wall biopsies in lean and obese control and obese NIDDM subjects, and incubated for $30 \mathrm{~min}$ at $37^{\circ} \mathrm{C}$ in the absence (hatched bars) and presence (open bars) of maximal insulin (100 $\mathrm{ng} / \mathrm{ml}$ ). The cells were then homogenized and PM (top) and LDM (bottom) subfractions were isolated by differential centrifugation. In these membrane subfractions, cytochalasin B binding was measured in the absence and presence of $500 \mathrm{mM}$ D-glucose for each ligand concentration (42-420 nM) and the difference was taken as the Dglucose-inhibitable component. These latter data were analyzed on Scatchard plots to determine the number $\left(R_{\mathrm{o}}\right)$ of D-glucose-inhibitable cytochalasin B binding sites (i.e., glucose transporters) in each membrane preparation. 
$\mathrm{pmol} / \mathrm{mg}$ in the lean controls. In obese NIDDM patients, the number of glucose transporters in LDM was even further decreased $(P<0.01)$ by $53 \%(3.2 \pm 0.4 \mathrm{pmol} / \mathrm{mg})$ compared with obese controls. In this intracellular compartment, the concentration of transporters thus was decreased in obesity and even further depleted in obese NIDDM subjects.

Acute stimulation by maximal insulin led to an increase in PM glucose transporters and a concomitant decrease in LDM in all subject groups (Fig. 3). Again, however, quantitative differences were apparent. In maximally stimulated cells, plasma membrane transporters were decreased by 20 and $50 \%$, and low-density microsomal carriers were decreased by 29 and $63 \%$, in the obese control and NIDDM subgroups, respectively, when compared with the value $(8.0 \pm 0.8 \mathrm{pmol} / \mathrm{mg})$ in the lean controls $(P<0.05)$. When the obese subgroups were directly compared, NIDDM patients had fewer transporters in both PM (38\%) and LDM (51\%) than their nondiabetic counterparts $(P<0.05)$. Within the obese control and NIDDM subgroups, there were no significant differences between males and females in the number of glucose transporters in any of the membrane subfractions (data not shown).

Note that the division of control subjects into lean and obese subgroups based on BMI above and below 29 was arbitrary. Therefore, to further assess the impact of obesity, we examined the effect of cell size along a continuum by performing correlation analysis between the number of membrane transporters and adipocyte volume. These data are shown in Fig. 4 for PM isolated from maximally insulin-stimulated cells (Fig. $4 \mathrm{~A}$ ) and for LDM from basal adipocytes (Fig. 4 $B)$. In nondiabetic subjects, the density of plasma membrane glucose transporters tended to decrease with enlarging cell size with an $r$ value of -0.44 ; this did not, however, achieve statistical significance $(0.05<P<0.10)$. In contrast, in the LDM, we observed a highly significant $(r=-0.87 ; P<0.01)$ inverse correlation between cell size $(246$ to $977 \mathrm{pl})$ and the number of glucose transporters ( 16 to $5 \mathrm{pmol} / \mathrm{mg}$ ). Although the mean adipocyte volume was $>500 \mathrm{pl}$ in all diabetic patients, the data correlating cell size and membrane transporters in
NIDDM is included in Fig. 4 for comparison purposes. From this analysis, it is clear that increasing adipocyte size is associated with a reduced concentration of LDM transporters in control subjects. Although it is important to take cell size into account when comparing various subject groups, we are able to directly assess the impact of NIDDM because the mean adipocyte volume $(713 \pm 47 \mathrm{pl})$ in our diabetic patients was similar $(P=\mathrm{NS})$ to that in the obese controls $(733 \pm 60 \mathrm{pl})$. Thus, these data strengthen our conclusion that PM and LDM glucose transporters are further depleted by NIDDM.

We also assayed glucose transporters in the HDM; the mean data in each subgroup are shown in Fig. 5. Two features of the data were clearly apparent. First, the concentration of transporters did not change in response to insulin in any of the subject groups $(P=\mathrm{NS})$. Secondly, unlike the other membrane subfractions, the number of transporters in the obese control and diabetic subgroups was similar to that in lean controls ( $P$ $=$ NS). These data suggest that depletion of cellular glucose transporters did not involve the HDM compartment in obesity and NIDDM.

The dissociation constants $\left(K_{d}\right)$ for D-glucose-inhibitable cytochalasin B binding to the various membrane subfractions were also measured and mean values are shown in Table II. Interestingly, both obese subgroups had $K_{d}$ values that were higher in all three membrane subfractions than in the lean controls, although these differences were not statistically significant in all instances (see Table II). Also, in lean control subjects but not in both obese subgroups, $K_{d}$ had a greater tendency to increase in LDM (i.e., lower affinity) than in PM and HDM $(P<0.05$, except $P=\mathrm{NS}$ for PM vs. LDM in insulin-stimulated cells).

Marker enzyme activities. Major changes in the fractionation of cells and in the recovery of membrane protein could affect the relative number of glucose transporters among the various subject groups. Therefore, we measured marker enzyme activities in the cellular homogenate and in each of the membrane subfractions, including 5'-nucleotidase (29) as a marker for PM, galactosyl-transferase (30) for LDM, and ro-

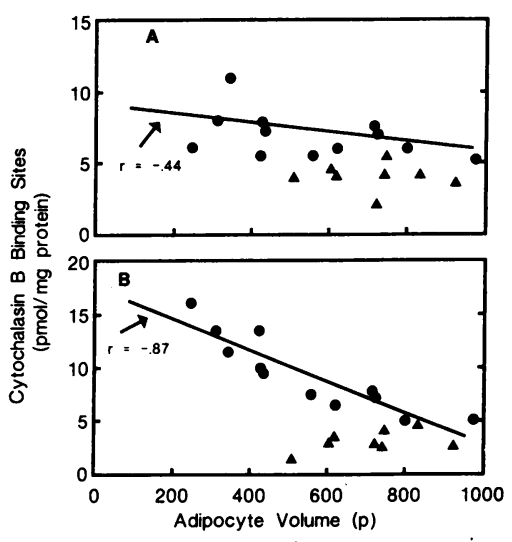

The cells were homogenized and PM were prepared from insulinstimulated cells $(A)$ and LDM prepared from basal cells $(B)$ by differential centrifugation. The number of D-glucose-inhibitable cytochalasin B binding sites was measured as described for Fig. 3. Mean adipocyte volume was assessed before homogenization using an eyepiece micrometer to measure diameter and assuming that cells were spherical. Linear regression of the discrete data is shown for control subjects only. between adipocyte size and the number of $D-$ glucose-inhibitable cytochalasin B binding sites in subcellular membrane fractions. Isolated adipocytes were prepared from abdominal wall biopsies in con-

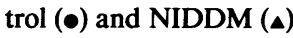
subjects and were incubated in the absence and presence of maxi$\mathrm{mal}$ insulin $(100 \mathrm{ng} / \mathrm{ml})$ for $30 \mathrm{~min}$ at $37^{\circ} \mathrm{C}$. fer-

Figure 4. Relationship 
Table II. Effects of NIDDM and Obesity on the $K_{d}$ Value for D-Glucose-Inhibitable Cytochalasin B Binding to Adipocyte Membrane Subfractions

\begin{tabular}{lccc}
\hline & \multicolumn{3}{c}{$K_{\mathbf{d}}$} \\
\cline { 2 - 4 } \multicolumn{1}{c}{ Subject group } & $\begin{array}{c}\text { Plasma } \\
\text { membranes }\end{array}$ & $\begin{array}{c}\text { Low-density } \\
\text { microsomes }\end{array}$ & $\begin{array}{c}\text { High-density } \\
\text { microsomes }\end{array}$ \\
\hline & & $n M$ \\
Lean controls & & & \\
$\quad$ Basal & $79 \pm 9$ & $98 \pm 5$ & $64 \pm 7$ \\
$\quad$ Maximally stimulated & $79 \pm 11$ & $99 \pm 10$ & $60 \pm 6$ \\
$\begin{array}{l}\text { Obese controls } \\
\text { Basal }\end{array}$ & $110 \pm 16^{*}$ & $125 \pm 11^{\ddagger}$ & $129 \pm 19^{\S}$ \\
$\quad$ Maximally stimulated & $130 \pm 27^{\ddagger}$ & $130 \pm 15^{*}$ & $110 \pm 12^{\S}$ \\
$\begin{array}{l}\text { Obese NIDDM } \\
\text { Basal }\end{array}$ & $106 \pm 10^{*}$ & $128 \pm 20^{\ddagger}$ & $117 \pm 19^{\ddagger}$ \\
$\quad$ Maximally stimulated & $112 \pm 13^{\ddagger}$ & $132 \pm 13^{\ddagger}$ & $120 \pm 21^{\ddagger}$ \\
& & &
\end{tabular}

Isolated adipocytes were prepared from abdominal wall biopsies and incubated under basal conditions or with maximal insulin (100 $\mathrm{ng} / \mathrm{ml}$ ) for $30 \mathrm{~min}$ at $37^{\circ} \mathrm{C}$. The cells were then homogenized, and plasma membrane and the microsomal subfractions were isolated by differential centrifugation. D-Glucose-inhibitable cytochalasin B binding to the membrane subfractions was measured as described for Fig. 3, and dissociation constants $\left(K_{d}\right)$ were determined by Scatchard analysis. In each subject group, the data are mean $\pm S E$ values of determinations in individuals. The statistical significance of differences between lean controls and the obese subgroups is indicated by ${ }^{*} P$ $=\mathrm{NS},{ }^{\ddagger} P<0.05$, and ${ }^{8} P<0.01$; membrane subfractions were compared separately in basal and stimulated cells.

tenone-insensitive cytochrome $c$ reductase (31) for HDM. Mean values for specific enzyme activity per milligram protein are shown in Table III, and the recovery of marker enzyme activities from homogenate is calculated in Table IV. Because insulin had no effect on the cellular distribution or recovery of these enzymes, data from basal and insulin-stimulated cells were combined.

From these data, several salient points emerge. First, when each membrane subfraction was compared among the subject groups, all marker enzymes had similar activities per milligram protein (Table III), with one exception. Adipocytes from NIDDM patients had $\sim 4$-fold higher 5'-nucleotidase activity (per milligram protein) than in control subjects both in the cellular homogenate and in each membrane subfraction. However, the degree to which 5'-nucleotidase activity was enriched in the various membrane species was comparable to control subjects (Table III). In all subject groups, the relative enrichment over homogenate of all marker enzyme activities thus was similar in each of the membrane subfractions. Secondly, the relative degree of cross-contamination of marker enzyme activities in the membrane fractions was generally not affected by obesity or diabetes. We concluded that fractionation was comparable in cells from lean, obese, and NIDDM individuals, and major changes in fractionation could not explain altered concentrations of glucose transporters in these subgroups.

The measurement of marker enzyme activities also allowed us to estimate the number of transporters per cell. In these calculations, the number of glucose transporters that were recovered in each membrane subfraction was quantitated
Table III. Marker Enzyme Specific Activities in Subcellular Membrane Fractions from Human Adipocytes

\begin{tabular}{|c|c|c|c|}
\hline & \multicolumn{2}{|c|}{ Controls } & \multirow{2}{*}{$\frac{\text { NIDDM }}{\text { Obese }}$} \\
\hline & Lean & Obese & \\
\hline \multicolumn{4}{|c|}{$\begin{array}{l}\text { 5' Nucleotidase } \\
\quad(\text { nmol/mg per } h)\end{array}$} \\
\hline Homogenate & $3.9 \pm 1.6$ & $4.8 \pm 2.3$ & $14.0 \pm 5.1$ \\
\hline PM & $27.6 \pm 9.8$ & $38.1 \pm 13.1$ & $125.2 \pm 44.9$ \\
\hline LDM & $5.6 \pm 2.8$ & $6.3 \pm 1.4$ & $35.9 \pm 9.9$ \\
\hline HDM & $16.5 \pm 9.1$ & $13.6 \pm 3.9$ & $70.2 \pm 16.5$ \\
\hline \multicolumn{4}{|c|}{$\begin{array}{l}\text { Galactosyl-transferase } \\
\qquad(\mathrm{nmol} / \mathrm{mg} \text { per } 2 h)\end{array}$} \\
\hline Homogenate & $3.3 \pm 0.4$ & $2.8 \pm 0.2$ & $3.4 \pm 0.5$ \\
\hline PM & $4.4 \pm 0.9$ & $4.0 \pm 1.1$ & $4.5 \pm 1.2$ \\
\hline LDM & $23.1 \pm 6.4$ & $28.9 \pm 5.5$ & $22.9 \pm 3.8$ \\
\hline HDM & $13.6 \pm 3.6$ & $12.3 \pm 2.9$ & $11.3 \pm 0.5$ \\
\hline \multicolumn{4}{|c|}{$\begin{array}{r}\text { Cytochrome } c \text { reductase } \\
(\mathrm{mol} / \mathrm{mg} \text { per } \mathrm{min})\end{array}$} \\
\hline Homogenate & $1.08 \pm 0.13$ & $0.95 \pm 0.28$ & $0.78 \pm 0.10$ \\
\hline PM & $0.58 \pm 0.12$ & $0.43 \pm 0.07$ & $0.54 \pm 0.10$ \\
\hline LDM & $3.85 \pm 0.60$ & $3.75 \pm 0.98$ & $3.10 \pm 0.80$ \\
\hline HDM & $5.54 \pm 1.05$ & $4.03 \pm 0.69$ & $3.55 \pm 0.61$ \\
\hline
\end{tabular}

Membrane subfractions were prepared from isolated adipocytes by differential centrifugation. Marker enzyme activities were measured and normalized to milligrams of membrane protein; 5'-nucleotidase activity (29) was used as a marker for PM, UDP-galactose/ $N$-acetylglucosamine galactosyl-transferase activity (30) was used to mark the Golgi apparatus enriched in LDM, and rotenone-insensitive NADH-cytochrome $c$ reductase activity (30) was used to mark endoplasmic reticulum enriched in HDM. Specific marker enzyme activities were determined in duplicate from membrane fractions prepared from basal and insulin-stimulated cells, but these results were averaged since insulin did not alter enzymatic activities or recoveries. The data represent the mean $\pm S E$ of determination from four separate fractionations within each subject group.

by multiplying the transporter concentration (Figs. 3 and 5) by the amount of protein recovered in each subfraction. The total number of transporters present in the initial homogenate could then be calculated in each subfraction from the recovery of specific enzyme marker. The data were then normalized per cell by dividing by the total number of cells used to prepare the initial homogenate. Adipocyte glucose transporters thus were quantitated in each subject group and are shown in Table IV. These values highlight the decreased numbers of transporters in obesity and the more profound depletion of cellular carriers in NIDDM. Again, reduced numbers of cellular transporters characterize PM and LDM, but not the HDM. This analysis is valid to the extent that $(a)$ marker enzymes are specific for a given membrane species and are not found elsewhere in the cell, and $(b)$ glucose transporters cofractionate with enzyme markers in each membrane subfraction. Since cross-contamination is not insignificant (Table III), these values remain only an approximation of cellular glucose transporters in vivo; however, this would not affect the relative values between the subject groups since fractionalized recoveries were comparable.

Functional activity of glucose transporters. While cellular depletion of glucose transporters provides one explanation for reduced glucose transport rates in NIDDM and obesity, further analysis of the data indicated that the functional activity of glucose transporters may also be impaired. To illustrate the relationship between the number and function of transporters in the PM, in Fig. 6 we have juxtaposed the concentration of PM glucose transporters per milligram protein and the glucose 
Table IV. Number and Distribution of Cellular Glucose Transporters in Human Adipocytes

\begin{tabular}{|c|c|c|c|c|c|}
\hline \multirow[b]{2}{*}{ Subject group } & \multirow[b]{2}{*}{$\begin{array}{l}\text { Membrane } \\
\text { subfraction }\end{array}$} & \multirow[b]{2}{*}{$\begin{array}{l}\text { Protein } \\
\text { recovered }\end{array}$} & \multirow[b]{2}{*}{$\begin{array}{l}\text { Recovery of marker } \\
\text { enzyme activity }\end{array}$} & \multicolumn{2}{|c|}{ No. of glucose transporters per cell } \\
\hline & & & & Basal & Maximally stimulated \\
\hline & & pg/cell & \% of homogenate & & $\times 10^{5}$ \\
\hline \multirow[t]{3}{*}{ Lean controls } & PM & $27 \pm 7$ & $40 \pm 10$ & $2.1 \pm 0.3$ & $4.4 \pm 0.7$ \\
\hline & LDM & $34 \pm 5$ & $47 \pm 8$ & $6.0 \pm 1.0$ & $3.7 \pm 0.9$ \\
\hline & HDM & $17 \pm 4$ & $17 \pm 4$ & $4.1 \pm 0.6$ & $3.5 \pm 0.6$ \\
\hline \multirow[t]{3}{*}{ Obese controls } & PM & $20 \pm 5$ & $32 \pm 10$ & $2.3 \pm 0.2$ & $3.3 \pm 0.3$ \\
\hline & LDM & $32 \pm 3$ & $54 \pm 6$ & $3.0 \pm 0.2$ & $1.9 \pm 0.2$ \\
\hline & HDM & $17 \pm 3$ & $13 \pm 3$ & $3.9 \pm 0.4$ & $3.9 \pm 0.5$ \\
\hline \multirow[t]{3}{*}{ Obese NIDDM } & PM & $20 \pm 5$ & $30 \pm 8$ & $1.0 \pm 0.2$ & $2.0 \pm 0.3$ \\
\hline & LDM & $27 \pm 4$ & $30 \pm 4$ & $1.8 \pm 0.2$ & $1.4 \pm 0.3$ \\
\hline & HDM & $15 \pm 2$ & $11 \pm 1$ & $3.7 \pm 0.8$ & $4.8 \pm 1.0$ \\
\hline
\end{tabular}

Isolated adipocytes were prepared from abdominal wall biopsies and incubated in the absence and presence of maximal insulin (100 $\mathrm{ng} / \mathrm{nl}) \mathrm{for}$ $30 \mathrm{~min}$ at $37^{\circ} \mathrm{C}$. Basal and maximally stimulated cells were homogenized, and PM, LDM, and HDM were prepared by differential centrifugation. The protein recovered in each subfraction was measured and normalized for the number of cells used to prepare the initial homogenate. Marker enzyme activity was measured in the recovered pellets as described for Table III and expressed as a percentage of the respective total marker enzyme activity in the cellular homogenate. The percent recovery of marker enzyme activity serves as a measure of the recovery of each respective membrane subfraction and was used to calculate the total amount of cellular protein for each membrane species. This latter value was multiplied by the concentration of glucose transporters per milligram protein in each membrane subfraction to determine the number of transporters per cell in each membrane species. The data are the mean \pm SE results of four separate fractionations in each subject group. See text for the assumptions inherent in these calculations.

transport rate per cell surface area in each subject group. Furthermore, for comparison purposes, we have set the scales so that the relative values for PM glucose transporters and transport activity are equal in the lean controls under basal conditions (Fig. $6 \mathrm{~A}$ ). It then becomes apparent that basal glucose transport rates were reduced $76 \%$ in the obese controls even though the concentration of PM glucose transporters re-

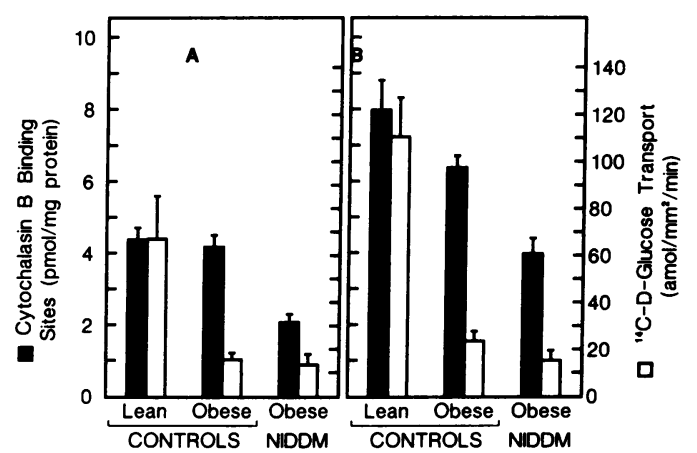

Figure 6. Functional activity of plasma membrane glucose transporters in human adipocytes. Isolated adipocytes were prepared from abdominal wall biopsies and were incubated under basal conditions $(A)$ and with maximal insulin $(B)$. In aliquots of cells, transport rates of trace $\left[{ }^{14} \mathrm{C}\right]$-D-glucose were measured (open bars) and normalized to square millimeters of cell surface area as in Fig. 2. The remaining cells were homogenized and the PM was prepared from basal and stimulated cells by differential centrifugation. The concentration of PM glucose transporters per milligram protein was measured (shaded bars) using the cytochalasin B binding assay as in Fig. 3. For comparison purposes, the scales are such that PM glucose transport rates per cell surface area and the density of PM glucose transporters per milligram protein are approximated under basal conditions in the lean controls. mained normal ( $P=$ NS from lean controls). Also, in the diabetic patients, basal transport activity was decreased to a greater extent than plasma membrane transporters ( 80 vs. $50 \%$ ). Therefore, in both obese subgroups, reduced rates of basal glucose transport per cell surface area could not totally be explained by changes in the concentration of PM glucose transporters. Similarly, in insulin-stimulated cells (Fig. $6 \mathrm{~B}$ ), there were also discrepancies between the number of PM glucose transporters and glucose transport rates in the obese control and NIDDM subjects. Specifically, the profound reduction in glucose transport rates in obese $(80 \%)$ and NIDDM patients $(88 \%)$ was much greater than the decrement in glucose transporter number (20 and $51 \%$, respectively) relative to the lean control subjects. These data suggest that the functional activity of glucose transporters is impaired in both obese subgroups.

While PM transporter activity was markedly impaired in obese individuals, closer examination of these data revealed an additional functional defect that may exist only in NIDDM. As can be seen in Fig. 6, insulin led to a $30 \%$ increase in both transporter number and transport rates in the obese controls, but there was only a minimal increment in the glucose transport rate in NIDDM, despite a doubling of glucose transporters. Therefore, the function of those transporters that translocate to the cell surface under the influence of insulin may be particularly impaired in diabetes. The same kind of analysis shows that, in basal cells, PM glucose transporters were decreased in NIDDM patients compared with obese controls even though transport rates were similar, suggesting that in NIDDM the activity of plasma membrane glucose transporters may be different in basal and insulin-stimulated cells. In any case, a profound functional defect present in both diabetic and nondiabetic obese individuals is an important mechanism of cellular insulin resistance. 


\section{Discussion}

A considerable body of evidence has indicated that defects distal to insulin-receptor binding are predominant in the pathogenesis of insulin resistance in NIDDM (1-9) and obesity $(34,35)$; however, the cellular and molecular events that impair insulin responsiveness are unknown. In the current study, insulin stimulated glucose transport in human adipocytes by recruiting intracellular glucose transporters (residing in the LDM) to the PM, with no effect on transporters in HDM. We found that specific abnormalities in both the number and functional activity of cellular glucose transport proteins were at least partially responsible for insulin's reduced ability to stimulate glucose uptake in adipocytes isolated from NIDDM and obese subjects.

When lean and obese nondiabetic subjects were compared, the number of PM glucose transporters was similar under basal conditions but declined in LDM with enlarging adipocyte size. Consequently, after stimulation by insulin, there were fewer PM glucose carriers in large adipocytes isolated from obese individuals because fewer intracellular transporters were available for translocation to the cell surface. In NIDDM, under basal and insulin-stimulated conditions, cells were profoundly depleted of glucose transporters in both PM and LDM relative to the obese controls. Therefore, in both obese and NIDDM patients, reduced numbers of glucose transporters contribute to the decreased rates of glucose transport in adipocytes. However, diminished transporter number was not the only transport abnormality in these patients. There appeared to be impaired functional activity of glucose carriers in both NIDDM and obesity, because decreased glucose transport rates could not be entirely explained by the decrement in the number of plasma membrane transporters. Impaired glucose transport thus was due to both a numerical and functional defect in transporters.

Although insulin-induced translocation of transporters has been demonstrated in human adipocytes $(18,19)$, these proteins have not been extensively studied in clinical states of insulin resistance. Karnieli et al. (19) have studied the effects of obesity on the number and cellular distribution of glucose transporters in omental adipocytes obtained during elective abdominal surgery. These investigators found that the concentration of glucose carriers in PM and LDM from both basal and insulin-stimulated cells was decreased $\sim 50 \%$ in obesity compared with lean control subjects. Also, after insulin stimulation, there was a discrepancy between glucose transport rates and the density of PM glucose transporters in obesity consistent with decreased activity of transporters. These previous results thus are in general agreement with the current data regarding diminished numbers and function of glucose transporters in obesity. We found, however, that cellular depletion of glucose transporters in obesity involved the LDM but not PM, and that there was a profound functional defect involving both basal and stimulated PM transporters. Perhaps these quantitative dissimilarities between the previous and current data are due to differences in omental vs. subcutaneous adipocytes (36) or due to surgery-induced elevations in counterregulatory hormones which could affect the glucose transport system $(37,38)$.

In diabetic patients, we also observed decreased number and function of adipocyte glucose transporters. However, the more profound defect in glucose uptake in NIDDM (vs. obesity per se) was explained in two ways. First, there was a greater depletion in the number of glucose transporters in NIDDM. The concentration of transporters was decreased by $\sim 50 \%$ in plasma membrane and low-density microsomal subfractions compared with weight-matched controls (Fig. 3) as was the estimate for total cellular transporters in these membrane subfractions (Table IV). It should also be noted that PM transporters under basal conditions were not decreased in obese controls but were significantly diminished in NIDDM. Secondly, the function of those transporters that translocate to the cell surface under the influence of insulin may be more severely impaired in NIDDM, since a doubling of PM glucose transporters was accompanied by only a minimal increment in the glucose transport rate. This is in contradistinction to nondiabetic obesity, in which insulin caused commensurate $30 \%$ increases in both plasma membrane transporters and transport rates.

Since the number and function of glucose transporters is dramatically affected by adipocyte size in nondiabetic subjects, it is necessary to control for cell size to assess the impact of diabetes on these parameters. We have satisfied this requirement because our obese control and diabetic subgroups had similar mean BMI and adipocyte volume. For example, in control subjects, there was a highly significant inverse correlation $(r=-0.87)$ between the number of glucose transporters in LDM and adipocyte volume (246-977 pl). When this relationship was examined in NIDDM (Fig. 4 B), LDM transporters were decreased relative to controls over the entire range of cell size studied. In fact, the relative discrepancy between the number of LDM transporters in control and NIDDM subjects was more marked in smaller cells $(7.2 \pm 0.4$ vs. $2.6 \pm 0.4 \mathrm{pmol} /$ $\mathrm{mg}$ in 500-724-pl cells) than in larger cells (5.8 4.7 vs. $3.4 \pm 0.5$ $\mathrm{pmol} / \mathrm{mg}$ in $725-1,000-\mathrm{pl}$ cells). The data suggest that the relative depletion of cellular transporters may be even more pronounced if we had compared lean control with lean NIDDM subjects (cell size $<500 \mathrm{pl}$ ), and this would be consistent with the fact that insulin resistance is almost equally as severe in lean and obese diabetic subjects (2).

It is interesting that the cellular content of transporters residing in the HDM is constant in lean and obese controls and NIDDM patients. In fact, the true number of HDM transporters may be elevated in NIDDM and obesity since the PM and LDM protein that contaminates this subfraction (Table III) would be depleted of transporters relative to the lean controls (Fig. 3). This observation has direct implications regarding the mechanism by which cells are depleted of glucose transporters in these patients. The HDM is enriched with endoplasmic reticulum $(24,29)$, the cellular organelle in which glucose transporters would be synthesized. Thus, the data suggest that transporter synthesis is normal (or elevated) and that cellular depletion occurs due to increased protein turnover once transporters leave this compartment. There is precedent for this mechanism since the ability of D-glucose to regulate glucose transporter number in fibroblasts is mediated posttranslationally through changes in transporter degradation (39).

There are several possible mechanisms that could impair the functional activity of transporters in NIDDM and obesity. One explanation would be a structural modification that decreases glucose transport activity. Interestingly, the $K_{d}$ for Dglucose-inhibitable cytochalasin B binding to transporters was 
higher (i.e., lower affinity) in obese control and NIDDM patients (relative to lean controls) which could result from structural alterations affecting ligand binding. On the other hand, other regulatory factors may negatively modulate transporter function. For example, ATP, cAMP, adenosine, and $\beta$-adrenergic agonists can modify the activity of glucose transporters independent of their cellular distribution (37, 40-43). Our finding that adipocyte 5 '-nucleotidase activity is elevated in untreated NIDDM represents a new observation, and could pertain to the functional regulation of transporters in these patients. It is possible to speculate that elevated 5'-nucleotidase activity may have either a causative or compensatory role in cellular insulin resistance by affecting levels of nucleotides (or nucleosides) known to modulate glucose transport. Along these lines, increased activity of this enzyme has also been observed in adipocytes (44) from streptozotocin-treated diabetic rats, and insulin treatment both increased glucose transport rates and normalized adipocyte 5 '-nucleotidase activity. Further investigation is needed to delineate the regulatory role of these compounds.

In summary, we have shown that cellular insulin resistance in NIDDM and obesity is due to both reduced numbers and impaired functional activity of glucose transporters, although this does not exclude other contributory cellular defects. The more profound cellular insulin resistance in NIDDM patients is associated with greater depletion in the number of glucose carriers as well as a further decrease in transporter functional activity.

\section{Acknowledgments}

The authors would like to thank Dr. Eddy Karnieli for helpful discussions regarding these data and for his comments in the preparation of this manuscript. We also thank Penny Wallace, R.N., Ginger Brechtel, R.N., and Jo Bell, R.N., for their indispensible assistance on the clinical research wards.

Dr. Garvey is a recipient of a Pfizer Scholars Award. Dr. Matthaei is a recipient of a grant from the Deutsche Forschungsgemeinschaft (Ma 985/2-1). This work was supported by research grants AM-33639 and AM-33651 from the National Institutes of Health (NIH); by grant PHS RR-00827 from the General Clinical Research Branch, Division of Research Resources, NIH; by the Veterans Administration Research Service; and the San Diego Veterans Administration Special Diagnostic and Treatment Center.

\section{References}

1. Reaven, G. M., R. Bernstein, B. Davis, and J. M. Olefsky. 1976. Non-ketotic diabetes mellitus: insulin deficiency or insulin resistance? Am. J. Med. 60:80-88.

2. Kolterman, O. G., R. S. Gray, J. Griffin, P. Burstein, J. Insel, J. A. Scarlett, and J. M. Olefsky. 1981. Receptor and postreceptor defects contribute to the insulin resistance in non-insulin-dependent diabetes mellitus. J. Clin. Invest. 68:957-969.

3. Ciaraldi, T. P., O. G. Kolterman, J. A. Scarlett, M. Kao, and J. M. Olefsky. 1982. Role of the glucose transport system in the postreceptor defect of non-insulin dependent diabetes mellitus. Diabetes. 31:1016-1022.

4. Kashiwagi, A., M. A. Verso, J. Andrews, B. Vasquez, G. Reaven, and J. E. Foley. 1983. In vitro insulin resistance of human adipocytes isolated from subjects with non-insulin-dependent diabetes mellitus. J. Clin. Invest. 72:1246-1254.

5. Scarlett, J. A., O. G. Kolterman, T. P. Ciaraldi, M. Kao, and J. M. Olefsky. 1983. Insulin treatment reverses the postreceptor defect in adipocyte 3-0-methyl glucose transport in Type II diabetes mellitus. J. Clin. Endocrinol. \& Metab. 56:1195-1201.

6. Foley, J. E., A. Kashiwagi, M. A. Verso, G. Reaven, and J. Andrews. 1983. Improvement in in vitro insulin action after one month of insulin therapy in obese non-insulin-dependent diabetes. $J$. Clin. Invest. 72:1901-1909.

7. Garvey, W. T., J. M. Olefsky, J. Griffin, R. F. Hamman, and O. G. Kolterman. 1985. The effect of insulin treatment on insulin secretion and insulin action in Type II diabetes mellitus. Diabetes. 34:222-234.

8. Scarlett, J. A., R. S. Gray, J. Griffin, J. M. Olefsky, and O. G. Kolterman. 1982. Insulin treatment reverses the insulin resistance of Type II diabetes mellitus. Diabetes Care. 5:353-363.

9. Andrews, W. J., B. Vasquez, M. Nagulesparan, I. Klimes, J. E. Foley, and R. Unger. 1984. Insulin therapy in obese NIDDM induces improvements in insulin action and secretion that are maintained for two weeks after insulin withdrawal. Diabetes. 33:634-642.

10. Wardzala, L., S. Cushman, and L. Salans. 1978. Mechanism of insulin action on glucose transport in the isolated rat adipose cell. $J$. Biol. Chem. 253:8002-8005.

11. Cushman, S. W., and L. J. Wardzala. 1980. Potential mechanisms of insulin action on glucose transport in the isolated rat adipose cell: apparent translocation of intracellular transport systems to the plasma membrane. J. Biol. Chem. 255:4758-4762.

12. Karnieli, E., M. J. Zarnowski, P. J. Hissin, I. A. Simpson, L. B. Salans, and S. W. Cushman. 1981. Insulin-stimulated translocation of glucose transport systems in isolated rat adipose cell. Time course, reversal, and insulin concentration dependency, and relationship to glucose transport activity. J. Biol. Chem. 256:4772-4777.

13. Suzuki, K., and T. Kono. 1980. Evidence that insulin causes translocation of glucose transport activity to the plasma membrane from an intracellular storage site. Proc. Natl. Acad. Sci. USA. 77:2542-2545.

14. Kono, T., F. W. Robinson, F. W. Blevins, and O. Ezaki. 1982. Evidence that translocation of the glucose transport activity is the major mechanism of insulin action on glucose transport in fat cells. $J$. Biol. Chem. 257:10942-10947.

15. Wardzala, L. J., and B. Jeanrenaud. 1981. Potential mechanism of insulin action on glucose transport in the isolated rat diaphragm. $J$. Biol. Chem. 256:7090-7093.

16. Watanabe, T., M. M. Smith, F. W. Robinson, and T. Kono 1984. Insulin action on glucose transport in cardiac muscle. J. Biol. Chem. 259:13117-13122.

17. Ciaraldi, T. P., R. Horuk, and S. Matthaei. 1986. Biochemical and functional characterization of the rat liver glucose transport system: comparisons with the adipocyte glucose transport system. Biochem. J. 240:115-123.

18. Matthaei, S., W. T. Garvey, R. Horuk, T. P. Hueckstaedt, and J. M. Olefsky. 1987. Human adipocyte glucose transport system. Biochemical and functional heterogeneity of hexose carriers. J. Clin. Invest. 79:703-709.

19. Karnieli, E., A. Barzilai, R. Rafaeloff, and M. Armoni. 1986. Distribution of glucose transporters in membrane fractions isolated from human adipose cells. Relation to cell size. J. Clin. Invest. 78:1051-1055.

20. Karnieli, E., P. J. Hissin, I. A. Simpson, L. B. Salans, and S. W. Cushman. 1981. A possible mechanism of insulin resistance in the rat adipose cell in streptozotocin-induced diabetes mellitus. J. Clin. Invest. 68:811-814.

21. Garvey, W. T., J. M. Olefsky, S. Matthaei, and S. Marshall. 1987. Glucose and insulin co-regulate the glucose transport system in primary cultured adipocytes: a new mechanism of insulin resistance. $J$. Biol. Chem. 262:189-197.

22. National Diabetes Data Group. 1979. Classification and diagnosis of diabetes mellitus and other categories of glucose intolerance. Diabetes. 28:1039-1057.

23. Ciaraldi, T. P., O. G. Kolterman, J. A. Siegel, and J. M. Olefsky. 
1979. Insulin stimulated glucose transport in human adipocytes. $\mathrm{Am}$. J. Physiol. 236:E621-E625.

24. McKeel, D. W., and L. Jarett. 1970. Preparation and characterization of a plasma membrane fraction from isolated fat cells. J. Cell Biol. 44:417-438.

25. Hirsch, J., and E. Gallian. 1968. Methods for the determination of adipose cell size in man and animals. J. Lipid Res. 9:110-119.

26. Marshall, S., W. T. Garvey, and M. Geller. 1984. Primary culture of isolated adipocytes: a new model to study insulin receptor regulation and insulin action. J. Biol. Chem. 259:6376-6384.

27. Foley, J. E. 1986. Measurement of in vitro glucose transport and metabolism in isolated human adipocytes. In Methods in Diabetes Research, Vol. II. W. L. Clarke, J. Larner, and S. L. Pohl, editors. John Wiley \& Sons, Inc., New York. 211-232.

28. Avruch, J., and D. F. H. Wallach. 1971. Preparation and properties of plasma membrane and endoplasmic reticulum fragments from isolated rat fat cells. Biochim. Biophys. Acta. 233:334-347.

29. Fleisher, B. 1974. Isolation and characterization of Golgi apparatus and membranes from rat liver. Methods Enzymol. 31:180-191.

30. Dallner, G., P. Siekevitz, and G. E. Palade. 1966. Biogenesis of endoplasmic reticulum membranes. J. Cell Biol. 30:97-117.

31. Bradford, M. 1976. A rapid and sensitive method for the quantitation of microgram quantities of protein utilizing the principle protein-dye bonding. Anal. Biochem. 72:248-254.

32. Desbuquois, B., and G. D. Aurbach. 1971. Use of polyethylene glycol to separate free and antibody-bound peptide hormones in radioimmunoassays. J. Clin. Endocrinol. \& Metab. 33:732-738.

33. Kuzuya, H., P. M. Blix, D. L. Horowitz, D. L. Steiner, and A. H. Rubenstein. 1977. Determination of free and total insulin and C-peptide in insulin-treated diabetics. Diabetes. 26:22-29.

34. Ciaraldi, T. P., O. G. Kolterman, and J. M. Olefsky. 1981. Mechanism of the postreceptor defect in insulin action in human obesity. Decrease in glucose transport system activity. J. Clin. Invest. 68:875-880.

35. Kolterman, O. G., J. Insel, M. Saekow, and J. M. Olefsky. 1980.
Mechanisms of insulin resistance in human obesity. Evidence for receptor and postreceptor defects. J. Clin. Invest. 65:1273-1284.

36. Bolinder, J., L. Kager, J. Ostman, and P. Arner. 1983. Differences at the receptor and postreceptor levels between human omental and subcutaneous adipose tissue in the action of insulin on lipolysis. Diabetes. 32:117-123.

37. Kashiwagi, A., T. P. Hueckstaedt, and J. E. Foley. 1983. The regulation of glucose transport by cAMP stimulators via three different mechanisms in rat and human adipocytes. J. Biol. Chem. 258:1368513692.

38. Carter-Su, C., and K. Okamoto. 1985. Effects of glucocorticoids on hexose transport in rat adipocytes: evidence for decreased transporters in the plasma membrane. J. Biol. Chem. 260:1109111098.

39. Haspel, H. C., E. W. Wilk, M. J. Birnbaum, S. W. Cushman, and O. M. Rosen. 1986. Glucose deprivation and hexose transporter polypeptides of murine fibroblasts. J. Biol. Chem. 261:6778-6789.

40. Smith, U., M. Kuroda, and I. A. Simpson. 1984. Counter-regulation of insulin-stimulated glucose transport by catecholamines in the isolated rat adipose cell. J. Biol. Chem. 259:8758-8763.

41. Joost, H. G., T. M. Weber, S. W. Cushman, and I. A. Simpson. 1986. Insulin-stimulated glucose transport in rat adipose cells: modulation of transporter intrinsic activity by isoproterenol and adenosine. J. Biol. Chem. 261:10033-10036.

42. Hebert, D. N., and A. Carruthers. 1986. Direct evidence for ATP modulation of sugar transport in human erythrocyte ghosts. $J$. Biol. Chem. 261:10093-10099.

43. Kuroda, M., R. C. Honnor, S. W. Cushman, C. Londos, and I. A. Simpson. 1987. Regulation of insulin-stimulated glucose transport in the isolated rat adipocyte: cAMP-independent effects of lipolytic and antilipolytic agents. J. Biol. Chem. 262:245-253.

44. Karnieli, E., M. Armoni, P. Cohen, Y. Kanter, and R. Rafaeloff. 1985. Reversal of insulin resistance of diabetic rats by insulin therapy: restoration of the pool of glucose transporters and enhancement of glucose transport activity. Diabetes. 34(Suppl. 1):77A. (Abstr.) 